\title{
PENGARUH IKLIM ORGANISASI TERHADAP KINERJA DENGAN MOTIVASI KERJA SEBAGAI VARIABEL INTERVENING
}

\author{
Fajri Nur Hidayat ${ }^{a}$ \\ Dwi Ratmawati ${ }^{\text {b }}$ \\ ${ }^{a}$ Sekolah Pascasarjana Universitas Airlangga ${ }^{\mathrm{b}}$ Fakultas Ekonomi dan Bisnis Universitas Airlangga \\ Email: fnurhidayat@yandex.com ; dwi.ratmawati@feb.unair.ac.id ${ }^{b}$
}

\section{ARTICLE HISTORY}

Received:

12 July 2019

Revised

14 August 2019

Accepted:

1 September 2019

Online available:

10 November 2019

Keywords (Calibri 10):

organizational climate, motivation,

performance

Kata Kunci:

iklim organisasi, motivasi kerja, kinerja

\begin{abstract}
Introduction: Division of research and development to produce performance played a central role in the form of technological innovation cultivation of sugar cane and innovation performance of the global industrial competition. Required organizational climate that support performance improvement and business development research staff. Mutual support and encouragement in every settlement between management and employees work will provide a comfortable atmosphere in the performance of employees. High motivation for staff to be able to grow a maximum potential and competence of employees wants to work hard to realize the company's strategic objectives.

Methods: To examine these issues, a questionnaire distributed to 35 staff in research and development of PTPNXI (Persero). The collected data were analyzed using SPSS analysis techniques.

Results: The results showed that the significant effect of organizational climate on employee performance. Thus a good organizational climate will cause the employee improve performance. Good organizational climate and always oriented employment relationship in shaping the behavior of employees can motivate employees that will result in optimal performance of employees at work.

Conclusion and suggestion: Managerial advice to do is apply organizational climate in PTPN XI (Persero) staff research and development efforts should be made clear again that the work climate that is able to adapt to the situation and condition of the employee. The next suggestion, leaders continue to increase employee motivation by not ignoring the rights and interests of employees as provide promotional opportunities, improved employee supervision system, increase confidence in the leadership, and maintain harmonious relationships between colleagues.
\end{abstract}




\begin{abstract}
ABSTRAK
Bidang penelitian dan pengembangan usaha atau dikenal PPU merupakan bagian dari Direktorat Perencanaan dan Pengembagan. Program yang dilaksanakan meliputi dua hal yaitu program rutin dan program non rutin. Bidang penelitian dan pengembangan usaha beperan penting untuk menghasilkan kinerja berupa inovasi teknologi budidaya tanaman tebu dan inovasi kinerja menghadapi persaingan industri global. Diperlukan iklim organisasi yang mendukung peningkatan kinerja staf penelitian dan pengembangan usaha. Saling memberikan dukungan dan semangat dalam setiap penyelesaian pekerjaan antara pimpinan dan karyawan akan memberikan suasana nyaman dalam kinerja karyawan. Motivasi kerja yang tinggi bagi staf PPU untuk bisa menumbuhkan potensi maksimal dan kompentensi karyawan agar mau bekerja keras mewujudkan tujuan strategis perusahaan. Untuk menguji permasalahan tersebut, kuisioner disebarkan pada 35 staf bidang penelitian dan pengembangan usaha PT. Perkebunan Nusantara XI (Persero). Data yang terkumpul kemudian dianalisis menggunakan teknik analisis SPSS.

Hasil penelitian menunjukkan bahwa iklim organisasi berpengaruh signifikan terhadap kinerja karyawan. Dengan demikian iklim organisasi yang baik akan menyebabkan karyawan meningkatkan kinerja. Iklim organisasi yang baik dan senantiasa berorientasi hubungan pekerjaan dalam membentuk perilaku karyawan bisa memotivasi karyawan sehingga akan menghasilkan kinerja optimal karyawan dalam bekerja.

Atas dasar hasil penelitian ini, saran manajerial yang dapat dilakukan adalah iklim organisasi yang diterapkan di PTPN XI (Persero) staf penelitian dan pengembangan usaha hendaknya lebih diperjelas lagi yaitu iklim kerja yang mampu menyesuaikan dengan situasi dan kondisi karyawan. Saran selanjutnya, para pemimpin terus meningkatkan motivasi kerja karyawan dengan cara tidak mengabaikan hak dan kepentingan karyawan seperti memberikan kesempatan promosi, perbaikan sistem pengawasan pegawai, meningkatkan kepercayaan terhadap pimpinan, dan menjaga hubungan harmonis antar rekan kerja.
\end{abstract}

\title{
INTRODUCTION
}

Kinerja karyawan merupakan suatu hasil yang dicapai oleh pekerja dalam pekerjaannya menurut kriteria tertentu yang berlaku untuk suatu pekerjaan tertentu. Pentingnya penilaian kinerja yang rasional dan diterapkan secara obyektif terlihat paling sedikit memiliki dua kepentingan (manfaat) baik bagi karyawan itu sendiri maupun bagi organisasi.

Salah satu perusahaan yang selalu memperhatikan kinerja karyawan adalah perusahaan perkebunan yang memiliki kompetitif tinggi dalam mengatasi persaingan. PT. Perkebunan Nusantara XI (Persero) adalah badan usaha milik negara (BUMN) 
agribisnis perkebunan dengan core bisnis gula.Perusahaan ini bahkan satu-satunya BUMN yang mengusahakan komoditas tunggal yakni gula dengan kontribusi sekitar 16$18 \%$ terhadap produk gula nasional. Pada kenyataannya industri gula Indonesia yang telah dibangun lebih dari empat abad silam ternyata tidak memunculkan produk-produk baru yang berhasil dikembangkan, sebagaimana industri perkebunan lainnya sebagian besar produk eksport merupakan bahan mentah.Industri gula masih saja berkonsentrasi pada gula putihnya dan mengesampingkan produk pendamping gula tebu atau lebih dikenal PPGT sebagaimana yang telah dilakukan negara-negara produsen gula dunia Dalam upayanya mengatasi permasalahan utama di atas diperlukan adanya perubahan struktural mendasar bagi perusahaan PTPN XI dalam hal ini perubahan struktural bagianpenelitian dan pengembangan usaha.

Hal terpenting yang harus diperhatikan agar meningkatkan kinerja karyawan adalah iklim organisasi dan motivasi kerja. Iklim organisasi bidang penelitian dan pengembangan usaha mendukung adanya motivasi untuk melakukan penelitian budidaya tanaman tebu. Iklim organisasi yang ada di PTPN XI yaitu suasana kerja karyawan yang kurang kondusif. Namun tingkat efektifitas komunikasi yang terjadi antar pimpinan dan karyawan belum optimal yang berdampak kesalah pahaman dalam pekerjaan dan kurangnya partisipasi seorang pemimpin yang membawahi karyawankaryawannya dalam melaksanakan tugas yang dibebankan kepada karyawan.

Bidang penelitian dan pengembangan usaha atau dikenal PPU merupakan bagian dari Direktorat Perencanaan dan Pengembangan semua program yang dilaksanakan adalah untuk mendukung tercapainya sasaran dan strategi Direktorat Perencanaan dan Pengembangan dan pada akhirnya mencapai sasaran dan strategi perusahaan. Program yang dilaksanakan meliputi dua hal, yaitu program rutin dan program non rutin. Program bersifat rutin seperti diskusi dan komunikasi dengan perguruan tinggi maupun lembaga penelitian untuk mendapatkan bahan percobaan yang dapat diterapkan di PTPN XI. Disamping itu juga melaksanakan program perawatan alat-alat laboratorium, mengikuti seminar, serta mengikuti pameran di dalam dan di luar daerah dengan topik yang sesuai dengan bidang kerja di penelitian dan pengembangan usaha.

Bidang penelitian dan pengembangan usaha berperan penting untuk menghasilkan kinerja berupa inovasi teknologi budidaya tanaman tebu dan inovasi kinerja menghadapi persaingan industri global. Iklim organisasi bidang penelitian dan pengembangan usaha mendukung adanya motivasi untuk melakukan penelitian budidaya tanaman tebu. Diperlukan iklim organisasi yang mendukung peningkatan kinerja staff penelitian dan pengembangan usaha (PPU). Iklim organisasi yang dimaksudkan saling memberi dukungan dan semangat dalam setiap menyelesaikan pekerjaan antara pimpinan dan karyawan akan memberikan suasana nyaman yang dapat 
meningkatkan kinerja karyawan. Memberi motivasi dan berinovasi untuk memunculkan kemampuan yang dimiliki karyawan tidak cukup dengan cara mendorong untuk berperilaku motivatif, tetapi lebih dari itu iklim organisasi merupakan faktor yang penting dalam usaha peningkatan kinerja karyawan di perusahaan.

Motivasi kerja yang tinggi merupakan hal penting bagi staff PPU untuk bisa menumbuhkan potensi maksimal dan kompentensi dalam dirinya agar mau bekerja keras mewujudkan tujuan strategis perusahaan.Menurut Sunarta (2014), motivasi dapat dimaknai sebagai keinginan (desire) dari dalam yang mendorong seseorang untuk bertindak. Kata motif disamakan artinya dengan motive, dorongan, dan alasan. Dengan demikian motivasi kerja adalah sesuatu yang menimbulkan dorongan atau Motivasi Kerja. Dorongan atau Motivasi Kerja sangat dipengaruhi oleh faktor pimpinan, teman kerja, sarana fisik, kebijakan organisasi, imbalan, jenis pekerjaan, dan tantangan.Sebagaimana Wursanto (1983) dalam Lieke (2013), tinggi rendahnya motivasi dipengaruhi banyak faktor diantaranya disiplin kerja tinggi, antusias kerja, iklim organisasi, loyalitas tinggi, kebutuhan kreatifitas, dan rasa kebanggan organisasi.

Karyawan yang berdaya akan banyak memberikan keuntungan baik dirinya sendiri maupun bagi organisai. Dalam jangka panjang, karyawan yang diberdayakan akan memberikan gagasan dan inisiatif bagi organisasi dalam menyelesaikan permasalahan yang dihadapi. Organisasi yang berdaya akan dipenuhi orang-orang yang memiliki kepedulian dan keterlibatan yang dapat membantu usaha pencapaian fleksibilitas serta responsivitas dalam lingkungan bisnis yang menantang dan kompetitif. Ken Blancard (2002), mengatakan bahwa pemberdayaan merupakan upaya memwirausahakan orang lain, penanaman rasa memiliki, bentuk ikatan kerja atas dasar komitmen, dan sebagai suatu usaha membuat orang lain terlibat, memberikan sumbangan positif dalam memelihara dan mempertahankan motivasi kerja karyawan.

Tujuan penelitian ini adalah (1) Menganalisis pengaruh iklim organisasi berpengaruh signifikan terhadap kinerja staf penelitian dan pengembangan usaha (PPU); (2) Menganalisis pengaruh iklim organisasi berpengaruh signifikan terhadap motivasi kerja staf penelitian dan pengembangan usaha (PPU) (3) Menganalisis pengaruh motivais kerja berpengaruh signifikan terhadap kinerja staf penelitian dan pengembangan usaha (PPU) (4) Menganalisis pengaruh iklim organisasi berpengaruh signifikan terhadap kinerja stafpenelitian dan pengembangan usaha (PPU) dengan motivasi kerja sebagai variabel intervening.

\section{LITERATURE REVIEW}

Penelitian mengenai pengaruh iklim organisasi terhadap kinerja dengan motivasi kerja sebagai variabel intervening telah banyak dilakukan seperti yang dikemukakan beberapa peneliti sebagai berikut: Pertama, Lubis (2008), dengan judul Pengaruh 
Pelatihan dan Motivasi Kerja Terhadap Kinerja Karyawan PT Perkebunan Nusantara IV (Persero) Medan. Penelitian ini menggunakan analisis teori manajemen sumber daya manusia. Populasi yang diambil seluruh karyawan pimpinan, pria dan wanita di Kantor Pusat PT Perkebunan Nusantara IV (Persero) Medan yang berjumlah 155 orang. Model analisis yang digunakan regresi linier berganda dengan menggunakan software SPSS. Hasil penelitian menunjukkan bahwa pelatihan dan motivasi kerja berpengaruh terhadap kinerja karyawan baik secara parsial maupun simultan. Nilai koefisien determinasi (R) diperoleh sebesar $8.81 \%$ hal ini berarti bahwa kemampuan variabel independen (pelatihan danmotivasi) menjelaskan pengaruhnya terhadap variabel dependen (kinerja karyawan) sebesar $8.81 \%$ sedangkan sisanya merupakan variabel tidak terungkap.

Kedua, Brahmasari dan Agus (2008), penelitian dengan judul Pengaruh Motivasi Kerja, Kepemimpinan dan Budaya Organisasi terhadap Kepuasan Kerja Serta Dampaknya pada Kinerja Perusahaan (Studi kasus pada PT. Pei Hai International Wiratama Indonesia). Hasil penelitian membuktikan bahwa motivasi kerja berpengaruh positif dan signifikan terhadap kepuasan kerja karyawan, artinya bahwa motivasi kerja memang sangat diperlukan oleh karyawan untuk dapat mencapai suatu kepuasan kerja yang tinggi meskipun menurut sifatnya kepuasan kerja itu sendiri besarannya sangat relatif atau berbeda antara satu orang dengan orang lainnya. Meskipun motivasi kerja berpengaruh signifikan terhadap kepuasan kerja tetapi belum tentu mempengaruhi kinerja perusahaan. Belum optimalnya kinerja seorang karyawan dibatasi oleh adanya kebijakan atasan misalnya berhubungan dengan waktu lembur. Yaitu karyawan yang telah terpuaskan kebutuhannya merasa bahwa manajemen telah memberikan penghargaan kepada dirinya sehingga merasa harus bekerja profesional artinya apabila terdapat pekerjaan yang belum selesai pada hari tersebut maka karyawan bermaksud menyelesaikan pekerjaan tanpa diperhitungkan waktu lembur. Karyawan tersebut memiliki dedikasi dan loyalitas terhadap pekerjaan, akan tetapi pihak manajemen menentukan bahwa sesuai ketentuan yang ada hal tersebut tidak diperkenankan.

Ketiga, Cahyono dan Dewi (2010) dengan judul Pengaruh Gaya Kepemimpinan, Motivasi Kerja dan Iklim Organisasi terhadap Prestasi Kerja Karyawan Bagian Engeneering Pada PT. Arabikatama Khatulistiwa Fishin Industry Depansar. Dalam penelitian ini menggunakan data primer yang bersumber dari observasi langsung dan kuisioner. Hasil penelitian menunjukkan bahwa variabel gaya kepemimpinan, motivasi kerja dan iklim organisasi berpengaruh signifikan secara simultan terhadap prestasi kesrja karyawan. Varibel motivasi kerja merupakan variabel yang berpengaruh dominan terhadap prestasi kerja karyawan secara simultan dan parsial. Variabel iklim organisasi berpengaruh positif dan signifikan secara parsial kepada prestasi kerja yang berarti iklim organisasi yang baik dapat meningkatkan prestasi kerja karyawan. 
Keempat, Putter (2010) dengan judul Organizational Climate and Performance "The Relation Between Organizational Climate and Performance and an Investigation of the Antecedents of Organizational Climate". Dalam penelitian ini hubungan antara iklim organisasi dan kinerja organisasi diuji pada perusahaan multinasional. Selain itu diuji pengaruh dukungan manajemen dan ukuran unit organisasi terhadap persepsi iklim organisasi. Hasilnya terdapat hubungan signifikan antara iklim organisasi dan profitabilitas, pertumbuhan dan perkembangan perusahaan, produktivitas dan keterlibatan karyawan. Tidak ada hubungan antara iklim organisasi dan pergantian karyawan. Tidak ada bukti bahwa hubungan antara iklim organisasi dan profitabilitas, pertumbuhan dan perkembangan perusahaan, dan produktivitas dimediasi oleh keterlibatan karyawan. Bahwa iklim organisasi sangat dipengaruhi oleh dukungan manajemen, hubungan antara ukuran unit organisasi dan iklim organisasi dimediasi oleh dukungan manajemen.

Pengaruh iklim organisasi (X1) terhadap kinerja $(Y)$

Penelitian ini menguji pengaruh iklim organisasi terhadap kinerja. Menurut Organisation Effectiveness and Development (2006), iklim organisasi merupakan bagian menyeluruh dari lingkungan kerja yang merupakan prespektif semua karyawan yang bekerja pada lingkungan organisasi tersebut. Mempengaruhi motivasi kerja dan perilaku kerja yang dapat memberikan efek jangka panjang pada motivasi karyawan, perilaku karyawan, serta produktifitas dan kinerja organisasi. Menurut Atkinson dan Frechette (2009), bagaimana bekerja di tempat yang mampu memotivasi karyawan dan menumbuhkan rasa kepemilikan, manajer harus memahami umpan balik, dan beberapa metode agar organisasi mendapatkan keuntungan dari iklim organisasi yang positif. Menurut Greenberg dan Baron (1993:74) iklim organisasi yang baik mampu menumbuhkan komitmen yang besar dari para anggotanya, merasa memiliki organisasi dan loyalitas tinggi dari anggota. Menurut Idrus (2006), lingkungan kerja yang menyenangkan membuat sikap pegawai lebih positif dan memberi motivasi untuk bekerja lebih tekun dan lebih baik. Sebaliknya lingkungan kerja tidak menyenangkan karyawan cenderung meninggalkan lingkungan tersebut.

Pengaruh iklim organisasi (X2) terhadap kinerja (Y) melalui motivasi kerja (Z) sebagai variabel intervening.

Motivasi kerja adalah dorongan yang muncul dari dalam diri karyawan untuk melaksanakan suatu pekerjaan dalam rangka memenuhi keinginan dan harapan serta imbalan yang ingin dicapai untuk memenuhi kebutuhannya (Laswitarni, 2013). Menurut Sangwan (2005), bahwa faktor-faktor motivasi kerja yang paling penting diantara perusahaan swasta dan publik diantaranya gaji, prospek karir, citra organisasi, sifat pekerjaan, keamanan kerja, lingkungan kerja, jam kerja, kekuasaan dan otoritas dalam pekerjaan. Motivasi kerja berasal dari dalam diri atau motivasi intrinsikadalah faktor- 
faktor yang berasal dari dalam diri karyawan berhubungan dengan kepuasan, antara lain kepuasan dalam berkarir, pengakuan yang diperoleh dari institusi, sifat pekerjaan yang dilakukan, peluang dan kemajuan dalam berkarir, pertumbuhan profesional dan intelektual yang dialami seseorang. Ditambahkan Kinman et al (2001), faktor-faktor intrinsik antara lain: ketertarikan pada pekerjaan, keinginan untuk berkembang, senang pada pekerjaannya, dan menikmati pekerjaannya.Motivasi ekstrinsik merupakan motivasi kerja yang bersumber dari luar seperti kebijakan organisasi, pelayanan administrasi, supervisi dari atasan, hubungan dengan teman kerja, kondisi pekerjaan, gaji yang diperoleh, dan ketenangan kerja (Cooke, 1999). Sedangkan menurut Kinman et al (2001), motivasi ekstrinsik antara lain: persaingan, evaluasi, status, uang dan penghargaan lainnya, dan menghindari hukuman dari atasan.

Berdasarkan kerangka konseptual di atas maka hipotesis penelitian ini adalah:

H1 : Iklim organisasi berpengaruh signifikan terhadap kinerja.

H2 : Iklim organisasi berpengaruh signifikan terhadap motivasi kerja.

H3 : Motivasi kerja berpengaruh terhadap kinerja

H4 : Iklim organisasi berpengaruh terhadap kinerja melalui motivasi kerja sebagai variabel intervening

\section{RESEARCH METHODS}

Penelitian ini menggunakan pendekatan secara kuantitatif dengan memberikan kuisioner kepada responden. Populasi yang akan diteliti adalah sinder kebun PT Perkebunan Nusantara XI bagian penelitian dan pengembangan berjumlah 35 orang. Responden dalam penelitian ini adalah seluruh staff penelitian dan pengembangan usaha PT. Perkebunan Nusantara XI pada bagian penelitian dan pengembangan tanaman tebu sejumlah populasi (35 orang).

Kuisoner menggunakan pola pertanyaan tertutup dengan alternatif jawaban telah disediakan. Dari setiap pertanyaan dan kolom isian responden yang ada dalam kuisoner, peneliti menggunakan skala Likert. Adapun skor sebagai berikut :

1. Sangat Setuju, diberi skor $=5$

2. Setuju, diberi skor $=4$

3. Ragu - ragu, diberi skor $=3$

4. Tidak Setuju, diberi skor $=2$

5. Sangat Tidak Setuju, diberi skor $=1$

Berikut ini adalah persamaannya :

$Z=\beta+\beta z x 1+e 1$ (persamaan 1)

$Y=\beta+\beta y z x 1+\beta z+e 2$. (persamaan 2)

Dimana : 


$$
\begin{aligned}
& Y=\text { Kinerja } \\
& Z=\text { Motivasi Kerja } \\
& X 1=\text { Iklim Organisasi } \\
& \beta=\text { koefisien variabel bebas } \\
& \text { e1,2 = variabel pengganggu }
\end{aligned}
$$

\section{RESULT AND ANALYSIS}

Tabel 1

Nilai Koefisien Jalur dan Pengujian Hipotesis

\begin{tabular}{llllll}
\hline \multirow{2}{*}{ Hipotesis } & Variabel & & Beta $(\beta)$ & t-hitung & $\rho$-value \\
\cline { 2 - 3 } & Bebas & Terikat & & & \\
\hline 1 & X & Z & 0,254 & 2,967 & 0,004 \\
2 & X & Y & 0,237 & 2,752 & 0,008 \\
3 & Z & Y & 0,022 & 2,164 & 0,029 \\
\hline
\end{tabular}

Tabel 3

Perhitungan Pengaruh Langsung, Pengaruh Tidak langsung dan Total Pengaruh

\begin{tabular}{llll}
\hline Keterangan & Pengaruh Langsung & $\begin{array}{l}\text { Pengaruh } \\
\text { TidakLangsung } \\
\text { (B) }\end{array}$ & Total Pengaruh \\
\hline Pengaruh X terhadap Z & & & C = A + B \\
\hline$X \rightarrow Z$ & $0,254=25,4 \%$ & - & $0,254=25,4 \%$ \\
\hline Pengaruh Z terhadap Y & & - & $0,022=2,2 \%$ \\
\hline$Z \rightarrow Y$ & $0,022=2,2 \%$ & - & $0,022=2,2 \%$ \\
\hline Total Pengaruh & $0,022=2,2 \%$ & \\
\hline Pengaruh X Terhadap Y & & & $0,237=23,7 \%$ \\
\hline$X \rightarrow Y$ & $0,237=23,7 \%$ & 0,005 \\
\hline$X \rightarrow Z \rightarrow Y$ & - & & $0,242=24,2 \%$ \\
\hline Total Pengaruh & $0,242=24,2 \%$ &
\end{tabular}

Sumber : Data diolah

\section{Pengaruh Iklim Organisasi terhadap Kinerja Karyawan}

Hasil penelitian ini menunjukkan ada pengaruh langsung faktor iklim organisasi terhadap kinerja karyawan PTPN XI. Dengan demikianiklim organisasi yang baikakan menyebabkan karyawan meningkatkan kinerjakaryawan. Iklim organisasi PTPN Xlyang dipersepsikan secara langsung berpengaruh positif terhadap kinerjakaryawan.Sedangkan pengaruh tidak langsung melalui motivasi kerja menunjukkan bahwa iklim organisasi berpengaruh terhadap kinerja karyawan jika motivasi kerja karyawan tercapai.

Hasil penelitian ini sesuai dengan pendapat Yuliandini (2004) yang menyatakan bahwa iklim organisasi dapat meningkatkan kinerja.Agar kinerja mempunyai nilai baik, iklim organisasi harus dilakukan secara timbal balik pula. Ini berarti menimbulkan unsur pengikutsertaan atasan dengan bawahan dan dengan kinerja atasan yang baik akan meningkatkan kinerja bawahan. 
Iklim organisasi berpengaruh positif terhadap kinerja karyawan.PTPN XI dalam meningkatkan iklim organisasi seluruh karyawan dengan memberikan informasi yang efektif dan membina hubungan antara karyawan maupun dengan perusahaan. Iklim organisasi yang dilakukan perusahaan/instansi dalam meningkatkan kinerja dilakukan dengan cara sering melakukan dialog dan seminar bagi karyawan atau pertemuan non formil yang dilakukan di luar kerja dalam rangka membina hubungan. Hal itu dilakukan untuk menjadi dorongan bagi karyawan PTPN XI untuk meningkatkan kinerja karyawan dalam mencapai tujuan perusahaan/instansi.

\section{Pengaruh Iklim organisasi terhadapMotivasi Kerja}

Hasil penelitian ini menunjukkan ada pengaruh langsung faktor iklim organisasi terhadap motivasi kerja karyawan PTPN XI (Persero). Dengan demikian, iklim organisasi yang baik akan menyebabkan karyawan meningkatkan motivasi kerja karyawan. Iklim organisasi PTPN XI (Persero) yang dipersepsikan secara langsung berpengaruh positif terhadap motivasi kerjakaryawan. Motivasi kerja mempunyai nilai baik, iklim organisasi harus dilakukan secara timbal balik pula.Berarti menimbulkan unsur pengikutsertaan atasan dengan bawahan dan dengan motivasi kerja atasan yang baik akan meningkatkan motivasi kerja bawahan.

Iklim organisasi berpengaruh positif terhadap motivasi kerja karyawan secara langsung Iklim organisasi yang dilakukan perusahaan/instansi dalam meningkatkan motivasi kerja dilakukan dengan cara meningkatkan perubahan struktur sesuai job disk karyawan, memberikan suasana kerja yang nyaman dan kondusif. Hal itu dilakukan untuk menjadi dorongan bagi karyawan PTPN XI untuk meningkatkan motivasi kerja karyawan dalam mencapai tujuan perusahaan/instansi.

\section{Pengaruh Motivasi Kerja terhadap Kinerja}

Hasil penelitian ini menunjukkan ada pengaruh langsung faktor motivasi kerja terhadap kinerja karyawan PTPN XI (Persero). Dengan demikian, motivasi kerja yang baik akan menyebabkan karyawan meningkatkan kinerja karyawan. Motivasi kerja PTPN XI (Persero) yang dipersepsikan secara langsung berpengaruh positif terhadap kinerjakaryawan. Kinerja mempunyai nilai baik, motivasi kerja harus dilakukan secara timbal balik pula.Berarti menimbulkan unsur pengikutsertaan atasan dengan bawahan dan dengan kinerja atasan yang baik akan meningkatkan kinerja bawahan.

Hasil penelitian ini mendukung pendapat Sedarmayanti (2007:233) yang menyatakan bahwa motivasi merupakan kesediaan mengeluarkan tingkat upah tinggi ke arah tujuan organisasi yang dikondisikan oleh kemampuan upaya itu untuk memenuhi kebutuhan individual. Unsur upaya merupakan ukuran intensitas. Bila seseorang termotivasi, ia akan mencoba kuat. Tujuan organisasi adalah upaya yang seharusnya. Kebutuhan sesuatu keadaan internal yang menyebabkan hasil tertentu tampak menarik. 
Motivasi merupakan timbulnya perilaku yang mengarah pada tujuan tertentu dengan penuh komitmen sampai tercapainya tujuan yang dimaksudkan

Faktor motivasi kerja berpengaruh positif terhadap kinerja karyawan PTPN XI (Persero) PTPN XI dalam meningkatkan motivasi dengan melakukan pembenahan seperti penghargaan, imbalan, seminar dan pelatihan supaya karyawan mampu termotivasi untuk bekerja lebih giat lagi untuk meningkatkan kinerja karyawan dalam mencapai tujuan perusahaan/instansi.

Pengaruh iklim organisasi (X2) terhadap kinerja (Y) melalui motivasi kerja (Z) sebagai variabel intervening.

Iklim organisasi (X2) berpengaruh positif terhadap kinerja (Y) melalui motivasi kerja (Z) sebagai variabel intervening Motivasi kerja adalah dorongan yang muncul dari dalam diri karyawan untuk melaksanakan suatu pekerjaan dalam rangka memenuhi keinginan dan harapan serta imbalan yang ingin dicapai untuk memenuhi kebutuhannya (Laswitarni, 2013).

Motivasi kerja berasal dari dalam diri atau motivasi intrinsikadalah faktor-faktor yang berasal dari dalam diri karyawan berhubungan dengan kepuasan, antara lain kepuasan dalam berkarir, pengakuan yang diperoleh dari institusi, sifat pekerjaan yang dilakukan, peluang dan kemajuan dalam berkarir, pertumbuhan profesional dan intelektual yang dialami seseorang.

Pengaruh tidak langsung iklim organisasi melalui motivasi kerja menunjukkan bahwa pelaksanaan iklim organisasi yang baik dan benar dapat meningkatkan motivasi kerja karyawan. Iklim organisasi yang baik dan senantiasa berorientasi hubungan pekerjaan dalam membentuk perilaku karyawan bisa memotivasi kerja karyawan sehingga akan meningkatkan hasil kerja yang optimal sehingga nantinya kinerja karyawan akan meningkat pula.Iklim organisasi memiliki pengaruh yang lebih besar daripada lingkungan kerja sehingga iklim organisasi lebih berpengaruh secara tidak langsung terhadap kinerja melalui motivasi kerja.

\section{CONCLUSION}

Berdasarkan hasil analisis data maka dapat disimpulkan hal-hal sebagai Iklim organisasi berpengaruh signifikan terhadap kinerja staf penelitian dan pengembangan usaha. Semakin baik iklim organisasi maka semakin tinggi kinerja. Iklim organisasi berpengaruh signifikan terhadap motivasi kerja staf penelitian dan pengembangan usaha. Semakin baik iklim organisasi maka semakin tinggi motivasi kerja. Motivasi kerja berpengaruh signifikan terhadap kinerja staf penelitian dan pengembangan usaha. Semakin baik motivasi kerja maka semakin tinggi kinerja. Iklim organisasi berpengaruh signifikan terhadap kinerja staf penelitian dan pengembangan usaha dengan motivasi 
kerja sebagai variabel intervening. Hal itu berarti motivasi kerja mampu menjadi perantara pengaruh iklim organisasi terhadap kinerja dengan melalui motivasi kerja.

Saran yang dapat diajukan antara lain:

1. Iklim Organisasi yang diterapkan di PTPN XI (Persero)Staf Penelitian dan Pengembangan Usaha hendaknya lebih diperjelas lagi, yaitu iklim kerja yang mengarah pada terbentuknya departemen reasearch and development.

2. Para pimpinan, diharapkan terus meningkatkan motivasi kerja pegawai dengan jalan tidak mengabaikan hak dan kepentingan pegawai yang bersangkutan. Seperti, memberikan kesempatan promosi, perbaikan sistem pengawasan pegawai, meningkatkan kemampuan dengan terus belajar memperbaiki kepribadian sehingga kepercayaan pada pimpinan selalu ada, dan menjaga harmonisnya hubungan antar rekan kerja.

3. Bidang Penelitian dan Pengembangan Usaha memiliki arahan yang jelas dalam melakukan perencanaan penelitian jangka panjang dan jangka pendek. Serta memberikan dukungan sepenuhnya seluruh staf PPU dalam melakukan upaya diseminasi teknologi seluruh unit usaha PTPN XI.

\section{REFERENCES}

Alavi, Hamid Reza dan Ramazan Jahandari. 2005. The Origanizational Climate Of Kerman Shahid Bahonar University. PublicPersonnelManagement. Vol. 34, no.3

Brahmasari, Ida Ayu dan Agus Suprayetno. 2008. Pengaruh Motivasi Kerja, Kepemimpinan dan Budaya Organisasi Terhadap Kepuasan Kerja Karyawan serta Dampaknya pada Kinerja Perusahaan (Studi kasus pada PT. Pei Hai International Wiratama Indonesia). Jurnal Manajemen dan Kewirausahaan. Vol 10. No 2. September 2008: 124-135.

Cahyono, Eko Aprihadi dan IGA Dewi Adnyani. 2010. Pengaruh Gaya Kepemimpinan, Motivasi Kerja dan Iklim Organisasi Terhadap Prestasi Kerja Karyawan Bagian Engeneering Pada PT. Arabikatama Khatulistiwa Fishing Industry Denpasar. Fakultas Ekonomi dan Bisnis Universitas Udayana. Bali.

Church, Allan H. 1995. Manajerial Behaviors and Work Group Climate as Predictors of Employee Outcomes. HumanBusinessDevelopmentQuarterly. Vol.6. 173-205.

Cherrington, David J. 1994. Organization Behavior; The Management of Individual and Organizational Performance, A DivisionofSimonofSchulterinc.

Fuad Mas'ud. 2004. Survai Diagnosis Organizational. Badan Penerbit Universitas Diponegoro. Semarang.

Grant, Ken et al. 2001. The Role of Satisfaction With Territory Design on The Motivation, Attitudes, and Work Outcomes of Salespeople. Journal of The Academy of Marketing Sciences. Vol. 23. No. 2, p 165-178

Greenberg, G. Dan R.A. Baron. 1993. Behavior In Organization, Third Edition, New Jersey: Prentice Hall Inc. 
Ghozali, I. 2006. Structural Equation Modeling: Metode Alternatif Dengan Partial Least Square (PLS), Semarang: Universitas Diponegoro.

Hermiati, E., D. Mangunwidjaja, T.C. Sunarti, O. Suparno, dan B. Prasetya. 2010. Pemanfaatan Biomassa Lignoselulosa Ampas Tebu Untuk Produksi Bioetanol. Jurnal Litbang Pertanian; 29(4).

Hadiyatno, Didik. 2012. Pengaruh Kompetensi, Kompensasi, dan Kepuasan Kerja Terhadap Kinerja Karyawan pada PT. Ciomas Adisatwa Balikpapan. http://www.journal.unipdu.ac.id/index.php/seminas/article/download/140/80

Ibrahim, Hasanuddin. 2004. Membangun Sistem Produksi Perkebunan Berdasarkan Kompetensi. Sekretaris III PP PERHEPI 2000-2003; Direktur Tanaman Semusim, Ditjen Bina Produksi Perkebunan.

Idrus, Muhammad. 2006. Implikasi Iklim Organisasi Terhadap Kepuasan Kerja dan Kualitas Kehidupan Kerja Karyawan.Jurnal Psikologi. Universitas Diponegoro. Vol 3 no 1.

Jogiyanto. 2009. Teori Portofolio dan Analisis Investasi. Penerbit: BPFE. Yogyakarta.

Ken Blancard. 2002. Empowerment (Take More Than a Minute). Amara Books, Yogyakarta.

Luthans, Fred. 2011. Organizational Behavior: An Evidence-Based Approach. McGrawHill. New York.

Lieke. 2013. Pengaruh Kompensasi dan Motivasi Kerja Terhadap Komitmen Organisasi di Organisasi Pendidikan Islam X. www.gunadarma.ac.id

Lubis, A. Khairul. 2008. Pengaruh Pelatihan dan Motivasi Kerja Terhadap Kinerja Karyawan PT Perkebunan Nusantara IV (Persero) Medan. Pasca Sarjana. Universitas Sumatera Utara.

Laswitarni, Ni Ketut. 2013. Budaya Organisasi, Kepuasan Kerja, Motivasi dan Kinerja Karyawan (Suatu Studi di PT Delta Satria Dewata Denpasar). www.stimidenpasar-jurnal.com

Nasution, S. 2008. Metode research (Penelitian Ilmiah). Jakarta: Bumi Aksara. Cetakan Kesepuluh. HIm 24.

Mardianto, Sudi. dkk. 2005. Peta Perjalanan (Road Map) dan Kebijakan Pengembangan Industri Gula Nasional.Pusat Litbang Sosial Ekonomi Pertanian; Pusat Penelitian Perkebunan Gula Indonesia.

Mathis, Robert L, dan Jackson, John H. 2002. Manajemen Sumber Daya Manusia. Salemba Empat. Jakarta.

Notoatmodjo, Soekidjo. 2003. Pengembangan Sumber Daya Manusia. Rineka Cipta. Jakarta.

Organisation Effectiveness and Development. 2006. LeadershipTools; OrganizationalClimate: A Proven Tool of improving Business Performance. www.oedconsulting.com

Putter, Lars. 2010. Organizational Climate and Performance "The Relation Between Organizational Climate and Performance and an Investigation of the Antecedents of Organizational Climate". Faculty of technology. Policy and Management. Delft University of Technology. 
Praditya, Ayu D. 2010.Pengaruh Kepuasan Kompensasi Financial Dan NonFinancial Terhadap Komitmen Affective, Continuance Dan Normative Pada Karyawan, Studi Kasus Pada Kantor Pusat PT Pembangkit Jawa-Bali Di Surabaya. Universitas Airlangga. Surabaya.

Pfeffer . J, Soetjipto Budi W, Handoko T. Hani, dkk. 2003. Paradigma Baru Manajemen Sumber Daya Manusia. Editor A. Usmara. Cetakan Keempat. Edisi Kedua. Amara Books. Yogyakarta.

Robbins, Stephen. P. 2002.Perilaku Organisasi, Konsep-Kontroversi-Aplikasi.Edisi Bahasa Indonesia.Jilid 1 dan 2. Alih Bahasa Hadyana Pujaatmara. PT Prenhallindo. Jakarta.

Robbins, S.P. 2008. Organization Behavior: Concept-Contraversies Aplication. New Jersey. Englewood Cliffs: Pretince-Hall, Inc.

Rivai, Veithzal. 2004. Kemimpinan dan Perilaku Organisasi. Edisi Kedua. Jakarta: PT. Raja Grafindo Persada.

Sunarta. 2014. Memelihara Motivasi Kerja Karyawan Untuk Meningkatkan Kinerja Organisasi. http://www.staff.uny.ac.id/sites/default/files

Shadur, Mark A; Kienzle Rene and Rodwell John J. 1999. The Relationship Between Organizational Climate and Employee Perception of Involvement. Group and Organizational Management. Vol. 24, no 4. December, pp.479-503.

Suwandi, Adig. 2013. Reasearch and Development Program PT. Perkebunan Nusantara XI, Tretes 29 s.d. 3 Mei 2013. www.ptpn-11.com/berita/penelitian-danpengembangan-usaha

Sangwan, D.S,.Proactive Human Resuorce Management: A Source Of Competitive Advantage. Vinimaya, XXXVI(4), pp. 35-43, 2005.

Sugiyono. 2009. Metode Penelitian Pendidikan Pendekatan Kuantitatif, Kualitatif, dan R\&D. Bandung: Alfabeta.

Suhartini, Yati. 2013. Pengaruh Faktor-Faktor Kompetensi Sumber Daya Manusia Terhadap Kinerja Karyawan (Studi Kasus pada Sales Supervisor Pertokoan Sepanjang Malioboro Yogyakarta). www.upy.ac.id

Setiyoningsih, Erlin. 2011. Pengaruh Motivasi, Kemampuan dan Kinerja Karyawan Terhadap Kepuasan Kerja dengan Kompensasi Sebagai Variable Moderator. Program Ilmu Manajemen Pascasarjana Fakultas Ekonomi. Universitas Brawijaya. Malang.

Tansuhaj, Patriya., Donna, Randall and Jim, McCullough. 1998. A Service Marketing Management Model: Integrating Internal and External Marketing Function. The Journal of Service Marketing. Vol.2, No.3

Vest M. J., Scott K.D., and Markham S.E. 1994. Self Rated Performance and Pay Satisfaction, Merit Increase Satisfaction and Isntrumentally Beliefs In A Merit

Pay Environment. Journal of Business and Psychology. Vol. 9. No. 2. p. 171-181

Wahjosumidjo. 1995. Kepemimpinan dan Motivasi. Jakarta: Ghalia Indonesia.

Wursanto. 1983. Manajemen Personalia. Jakarta: Pustaka Dian.

Published by University of Airlangga.

This is an open access article under the CC BY license (https://creativecommons.org/licenses/by-sa/4.0/) 
Jurnal Ekonomi dan Bisnis Airlangga, Vol. 29, No.2, June - November 2019

Wijayanto, Aris, Musa Hubies, M. Joko affandi, dan Aji Hermawan. 2011. Faktor-Faktor Yang Mempengaruhi Kompetensi Kerja Karyawan. Vol 6 no 2 (81-87). Manajemen IKM.

Wiyono, D. G. 2011. Merancang Penelitian Bisnis dengan Alat Analisis SPSS 17.0 dan SmartPLS 2.0. Yogyakarta: Unit Penerbit dan Percetakan STIM YKPN. 